\title{
Common Fixed Point Theorem in Intuitionistic Fuzzy Metric Space Satisfying Integral Type Inequality
}

\author{
Preeti Malviya $^{1}$, Vandna Gupta ${ }^{2}$, V.H. Badshah ${ }^{3}$ \\ ${ }^{1}$ Government New Science College, Dewas (M.P.), India \\ ${ }^{2}$ Government Kalidas Girl's College, Ujjain (M.P.), India \\ ${ }^{3}$ School of Studies in Mathematics, Vikram University, Ujjain (M.P.), India
}

\begin{abstract}
The aim of this paper is to present some common fixed point theorem in Intuitionistic fuzzy metric space satisfying integral type inequality for E.A. Property.
\end{abstract}

Keywords: Common fixed point, Fuzzy metric space, E.A. Property,Semi Compatible maps, Intuitionistic fuzzy metric space.

2000 Mathematics Subject Classification: 47H10, 54H25.

\section{Introduction}

The theory of fixed point equations in one of the basic tools to handle various physical formulations. Fuzzy set was defined by Zadeh [1]. Kramosil and MIchalek [2]. introduced fuzzy metric space. many authors extend their views. Grorge and Veermanyam [3]. modified the notion of fuzzy metric spaces with the help of continuous t-norms Grabiec[4].

In the recent year, several common fixed point theorems for contractive type mappings have been proved by several authors. Branciari [5],gave a fixed point result for a single mapping satisfying Banach's contraction principle for an integral type inequality.

Aliouche[6] established a common fixed point theorem for weakly compatible mappings in symmetric spaces satisfying a contrative condition of integral type and property (E.A.) introduced by Aamri and El. Moutawakil [7].

Boikanyo and Choudhary [8] prove some common fixed point theorem for pointwise R-weakly commuting mapping $\mathrm{s}$ in symmetric space.

K.Atanassov [9] introduced and studied the concept of intuitionistic fuzzy sets. In 2004, J.H.Park [10] define intuitionistic fuzzy metrice space with the help of continuous $\mathrm{t}$-norms and continuous $\mathrm{t}$-conforms.

In this paper, we obtain common fixed point theorem in Intuitionistic fuzzy metric space using E.A. property.

\section{Preliminary}

Definition 2.1 [11] A binary operation *:[0,1] x[0,1] $\rightarrow[0,1]$ is a continuous $\mathrm{t}$-norm if it satisfies the following conditions

(i ) *is associative and commutative

( ii ) *is continuous,
( iii ) $\mathrm{a}^{*} 1=\mathrm{a}$, for all $\mathrm{a} \in[0,1]$

(iv ) $\mathrm{a}^{*} \mathrm{~b} \leq \mathrm{c}^{*} \mathrm{~d}$, whenever $\mathrm{a} \leq \mathrm{c}$ and $\mathrm{b} \leq \mathrm{d}$, for all $\mathrm{a}, \mathrm{b}, \mathrm{c}, \mathrm{d} \in$ $[0,1]$.

Definition 2.2 [11] A binary operation $\diamond:[0,1] \times[0,1] \rightarrow[0,1]$ is a continuous $\mathrm{t}$-conorm if it satisfies the following conditions :

(i) \is associative and commutative

(ii ) $\searrow$ is continuous,

( iii ) $\mathrm{a} \diamond 1=\mathrm{a}$, for all a $\in[0,1]$

(iv ) $\mathrm{a} \diamond \mathrm{b} \leq \mathrm{c} \diamond \mathrm{d}$, whenever $\mathrm{a} \leq \mathrm{c}$ and $\mathrm{b} \leq \mathrm{d}$, for all $\mathrm{a}, \mathrm{b}, \mathrm{c}, \mathrm{d} \in$ $[0,1]$.

Definition 2.3 [12] A 5-tuple (X, M, N, *, $\diamond)$ is said to be an Intuitionistic fuzzy mertic space if $\mathrm{X}$ is an arbitrary set, $*$ is a continuous $\mathrm{t}$-norm, $\diamond$ is a continuous $\mathrm{t}$-conorm and $\mathrm{M}, \mathrm{N}$ are fuzzy sets on $X^{2} x[0, \infty)$ satisfying the following conditions.

(i ) $\mathrm{M}(\mathrm{x}, \mathrm{y}, \mathrm{t})+\mathrm{N}(\mathrm{x}, \mathrm{y}, \mathrm{t}) \leq 1$, for all $\mathrm{x}, \mathrm{y} \in \mathrm{X}$ and $\mathrm{t}>0$,

( ii ) $M(x, y, 0)=0$, for all $x, y \in X$,

(iii ) $\mathrm{M}(\mathrm{x}, \mathrm{y}, \mathrm{t})=1$, for all $\mathrm{x}, \mathrm{y} \in \mathrm{X}$ and $\mathrm{t}>0$, iff $\mathrm{x}=\mathrm{y}$,

(iv ) $\mathrm{M}(\mathrm{x}, \mathrm{y}, \mathrm{t})=\mathrm{M}(\mathrm{y}, \mathrm{x}, \mathrm{t})$, for all $\mathrm{x}, \mathrm{y} \in \mathrm{X}$ and $\mathrm{t}>0$,

( v ) $M(x, y, t)^{*} M(y, z, s) \leq M(x, z, t+s)$, for all $x, y \in X$ and $t, s$ $>0$,

( vi ) for all $\mathrm{x}, \mathrm{y} \in \mathrm{x}, \mathrm{M}(\mathrm{x}, \mathrm{y},):.[0, \infty) \rightarrow[0,1]$ is left continuous,

( vii ) $\lim _{\mathrm{t}} \rightarrow_{\infty} \mathrm{M}(\mathrm{x}, \mathrm{y}, \mathrm{t})=1$, for all $\mathrm{x}, \mathrm{y} \in \mathrm{X}$ and $\mathrm{t}>0$,

( viii ) $\mathrm{N}(\mathrm{x}, \mathrm{y}, 0)=1$, for all $\mathrm{x}, \mathrm{y} \in \mathrm{X}$,

( ix ) $\mathrm{N}(\mathrm{x}, \mathrm{y}, \mathrm{t})=0$, for all $\mathrm{x}, \mathrm{y} \in \mathrm{X}$ and $\mathrm{t}>0$, iff $\mathrm{x}=\mathrm{y}$,

( $x$ ) $N(x, y, t)=N(y, x, t)$, for all $x, y \in X$ and $t>0$,

( $x$ i ) $\mathrm{N}(\mathrm{x}, \mathrm{y}, \mathrm{t}) * \mathrm{~N}(\mathrm{y}, \mathrm{z}, \mathrm{s}) \leq \mathrm{N}(\mathrm{x}, \mathrm{z}, \mathrm{t}+\mathrm{s})$, for all $\mathrm{x}, \mathrm{y} \in \mathrm{X}$ and $\mathrm{t}, \mathrm{s}>$ 0 ,

( xii ) for all $\mathrm{x}, \mathrm{y} \in \mathrm{x}, \mathrm{N}(\mathrm{x}, \mathrm{y},):.[0, \infty) \rightarrow[0,1]$ is right continuous,

( xiii ) $\lim _{\mathrm{t}} \rightarrow_{\infty} \mathrm{N}(\mathrm{x}, \mathrm{y}, \mathrm{t})=0$, for all $\mathrm{x}, \mathrm{y} \in \mathrm{X}$.

Remark 2.1[13]

In intuitionistic metric fuzzy space $\left(\mathrm{X}, \mathrm{M},{ }^{*}\right)$ is an intuitionistic fuzzy space of the form $(\mathrm{X}, \mathrm{M}, 1-\mathrm{M}, *, \diamond)$, 


\section{International Journal of Science and Research (IJSR) \\ ISSN (Online): 2319-7064}

Index Copernicus Value (2013): 6.14 | Impact Factor (2015): 6.391

such that t-norm $*$ and t-conorm $\diamond$ are associated as $\mathrm{x} \oslash \mathrm{y}=1$ $((1-\mathrm{x}) *(1-\mathrm{y}))$ for all $\mathrm{x}, \mathrm{y} \in \mathrm{X}$.

\section{Remark 2.2[13]}

In intuitionistic fuzzy metric space $\left(\mathrm{X}, \mathrm{M}, \mathrm{N},{ }^{*}, \diamond\right), \mathrm{M}\left(\mathrm{x}, \mathrm{y},{ }^{*}\right)$ is non-decreasing and $\mathrm{N}(\mathrm{x}, \mathrm{y}, \diamond)$ is Non-increasing for all $\mathrm{x}, \mathrm{y}$ $\in X$.

Example 2.1 - Let $(X, d)$ be a metric space . Define $a * b=a b$ and $a \diamond b=\min \{1, a+b\}$ for all $a, b \in[0,1]$ and let $M_{d}$ and $N_{d}$ be a fuzzy sets on $X^{2} x(0, \infty)$ defined as

$\mathrm{M}_{\mathrm{d}}(\mathrm{x}, \mathrm{y}, \mathrm{t})=\mathrm{t} / \mathrm{t}+\mathrm{d}(\mathrm{x}, \mathrm{y}), \mathrm{N}_{\mathrm{d}}(\mathrm{x}, \mathrm{y}, \mathrm{t})=\mathrm{d}(\mathrm{x}, \mathrm{y}) / \mathrm{t}+\mathrm{d}(\mathrm{x}, \mathrm{y})$

Then $\left(X, M_{d}, N_{d}, *, \diamond\right)$ is an intuitioistic fuzzy metric space.

Definition 2.4[12] Let $\left(\mathrm{X}, \mathrm{M}, \mathrm{N},{ }^{*}, \diamond\right)$ be an intuitioistic fuzzy metric space. Then

( 1 ) A sequence $\left\{x_{n}\right\}$ in $X$ is set to be convergent to a point $\mathrm{X}$ in $X$ iff $\operatorname{Lim}_{n} \rightarrow_{\infty} M\left(x_{n}, x, t\right)=1$ and

$\lim _{n} \rightarrow_{\infty} N\left(x_{n}, x, t\right)=0$, for all $t>0$.

Lemma 2.1[12] Let $(X, M, N, *, \diamond)$ be an intuitionistic fuzzy metric space. If for all $\mathrm{x}, \mathrm{y} \in \mathrm{X}$ and $\mathrm{t}>0$ with positive number $\mathrm{k} \in(0,1)$ and $\mathrm{M}(\mathrm{x}, \mathrm{y}, \mathrm{kt}) \geq \mathrm{M}(\mathrm{x}, \mathrm{y}, \mathrm{t})$ and $\mathrm{N}(\mathrm{x}, \mathrm{y}, \mathrm{kt}) \leq$ $\mathrm{N}(\mathrm{x}, \mathrm{y}, \mathrm{t})$, then $\mathrm{x}=\mathrm{y}$.

Definition 2.5[13] A pair of self mappings ( $P, Q$ ) of a intuitionistic fuzzy metric space $(X, M, N, *, \diamond)$ is said to be compatible if $\lim _{\mathrm{n}} \rightarrow_{\infty} \mathrm{M}\left(\mathrm{PQx}_{\mathrm{n}}, \mathrm{QPx}_{\mathrm{n}}, \mathrm{t}\right)=1$ and $\lim _{\mathrm{n}} \rightarrow_{\infty}$ $\mathrm{N}\left(\mathrm{PQx}_{\mathrm{n}}, \mathrm{QPx}_{\mathrm{n}}, \mathrm{t}\right)=0$, for all $\mathrm{t}>0$.

When ever $\left\{\mathrm{X}_{\mathrm{n}}\right\}$ is a sequence in $\mathrm{X}$ such that

$\operatorname{Lim}_{n} \rightarrow_{\infty} P x_{n}=\operatorname{Lim}_{n} \rightarrow_{\infty} Q x_{n}=z$, for some $z \in X$.

Definition 2.6[14]A pair of self mappings ( $P$,Q ) of a intuitionistic fuzzy metric space $(X, M, N, *, \diamond)$ is said to be semi compatible if $\lim _{\mathrm{n}} \rightarrow_{\infty} \mathrm{PQx}_{\mathrm{n}}=\mathrm{Qx}$, When ever $\left\{\mathrm{x}_{\mathrm{n}}\right\}$ is a sequence in $\mathrm{X}$ such that

$\operatorname{Lim}_{n} \rightarrow_{\infty} \operatorname{Px}_{n}=\operatorname{Lim}_{n} \rightarrow_{\infty} \mathrm{Qx}_{\mathrm{n}}=\mathrm{x}$, for some $\mathrm{x} \in \mathrm{X}$.

Definition 2.7[7] A pair of self mapping ( $P, Q)$ on an intuitionistic fuzzy metric space $(X, M, N, *, \nabla)$ is said to satisfy the E.A. property if there exist a sequence $\left\{x_{n}\right\}$ in $X$ such that

$\lim _{n} \rightarrow_{\infty} P x_{n}=z=\lim _{n} \rightarrow_{\infty} Q x_{n}$ for some $z \in X$.

Definition 2.8[15] Mapping A, B, S and $\mathrm{T}$ on an intuitionsitic fuzzy metric space ( $\mathrm{X}, \mathrm{M}, \mathrm{N}, *, \diamond)$ ) are said to satisfy the common E.A. property if there exist a sequence $\left\{\mathrm{x}_{\mathrm{n}}\right\}$ and $\left\{\mathrm{y}_{\mathrm{n}}\right\}$ in $\mathrm{X}$ such that

$\lim _{n} \rightarrow_{\infty} B y_{n}=\lim _{n} \rightarrow_{\infty} \mathrm{Ty}_{\mathrm{n}}=\lim _{\mathrm{n}} \rightarrow_{\infty} \mathrm{Ax} x_{\mathrm{n}}=\lim _{\mathrm{n}} \rightarrow_{\infty} \mathrm{Sx}_{\mathrm{n}}=\mathrm{z}$ for some $\mathrm{z} \in \mathrm{X}$.

Theorem3.1 Let $\left(\mathrm{X}, \mathrm{M}, \mathrm{N},{ }^{*}, \diamond\right)$ be an Intuitionistic fuzzy metric space with continuous t- norm *and continuous tconorm $\diamond$. Let $\mathrm{P}, \mathrm{Q}, \mathrm{S}$ and $\mathrm{T}$ be self mappings on $\mathrm{X}$, satisfying the following properties ;

1. pair $(\mathrm{P}, \mathrm{S})$ and $(\mathrm{Q}, \mathrm{T})$ share the common property E.A.

2. $\mathrm{S}(\mathrm{X})$ and $\mathrm{T}(\mathrm{X})$ are closed subset of $\mathrm{X}$.

3. For any $\mathrm{x}, \mathrm{y} \in \mathrm{X}$ and for all $\mathrm{t}>0$ there exist

$\mathrm{k} \in(0,1)$ such that

$\int_{0}^{M(P x, Q y, k t)} \emptyset(t) d t \geq$

$\int_{0}^{\min [M(S x, T y, t) *[M(S x, P x, t) \cdot M(Q y, T y, t)\} * M(P x, T y, t)]} \emptyset(t) d t$
And,

$\int_{0}^{N(P x, Q y, k t)} \emptyset(t) d t \leq$

$\int_{0}^{\max [N(S x, T y, t) *\{N(S x, P x, t) \cdot N(Q y, T y, t)\} * N(P x, T y, t)]} \emptyset(t) d t$

For all $\mathrm{x}, \mathrm{y} \in \mathrm{X}$, where $\phi: \mathrm{R}^{+} \rightarrow \mathrm{R}^{+}$is a Lesbegue integrable mapping which is summable satisfying for each $0<\varepsilon<1$,

$0<\int_{0}^{\varepsilon} \varnothing(t) d t<1, \int_{0}^{1} \varnothing(t) d t=1$

Then each of pair $(\mathrm{P}, \mathrm{S})$ and $(\mathrm{Q}, \mathrm{T})$ have a point of coincidence. If the pairs $(\mathrm{P}, \mathrm{S})$ and $(\mathrm{Q}, \mathrm{T})$ are semi compatible , then $\mathrm{P}, \mathrm{Q}, \mathrm{S}$ and $\mathrm{T}$ have a unique common fixed point .

Proof - Since the pairs $(\mathrm{P}, \mathrm{S})$ and $(\mathrm{Q}, \mathrm{T})$ Share the common property (E.A.), then there exists two sequences $\left\{x_{n}\right\}$ and $\left\{\mathrm{y}_{\mathrm{n}}\right\}$ in $\mathrm{X}$ such that

$\lim _{n \rightarrow \infty} P x_{n}=\lim _{n \rightarrow \infty} S_{x n}=\lim _{n \rightarrow \infty} Q_{y_{n}}=\lim _{n \rightarrow \infty} T_{n}=z$, for some $z \in X$.

Since $S(X)$ is closed subset of $X$,therefore there exists a point $v \in X$ such that $z=S v$

Now, we prove that $\mathrm{Pv}=\mathrm{Z}$

By inequality (3), Putting $\mathrm{x}=\mathrm{v}$, and $\mathrm{y}=\mathrm{y}_{\mathrm{n}}$ we get

$\int_{0}^{\mathrm{M}(\mathrm{Pv}, \mathrm{Q}, \mathrm{kt})} \emptyset(\mathrm{t}) \mathrm{dt} \geq$

$\int_{0}^{\min \left[M\left(S v, T^{\prime}, \mathrm{t}\right) *\{M(S v, P v, t) \cdot M(Q, T, t)\} * M(P v, T, \mathrm{t})\right]} \emptyset(t) d t$

Taking $\lim \mathrm{y}_{\mathrm{n}} \rightarrow \infty$, we get $\quad \mathrm{y}_{\mathrm{n}} \quad \mathrm{y}_{\mathrm{n}} \quad \mathrm{y}_{\mathrm{n}}$

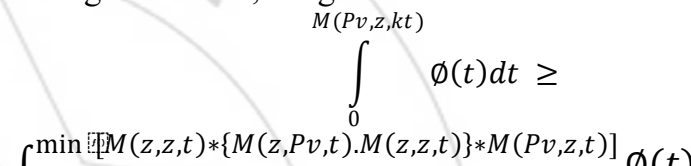

$\int_{0}^{\min [M(z, z, t) *\{M(z, P v, t) \cdot M(z, z, t)\} * M(P v, z, t)]} \emptyset(t) d t$

$\int_{0}^{M(P v, z, k t)} \emptyset(t) d t \geq$

$\left.\int_{0}^{\min [\top 1} *\{M(z, P v, t) \cdot 1\} * M(P v, z, t)\right] \emptyset(t) d t$

$\int_{0}^{M(P v, z, k t)} \emptyset(t) d t \geq \int_{0}^{M(z, P v, t)} \emptyset(t) d t$

Similarly,

$\int_{0}^{N(P v, Q, k t)} \emptyset(t) d t \leq$

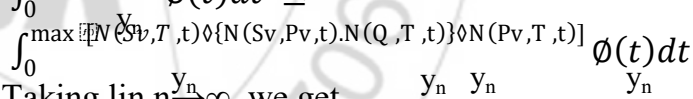

Taking lin $\mathrm{n} \stackrel{\mathrm{y}_{\mathrm{n}}}{\rightarrow}$, we get $\quad \mathrm{y}_{\mathrm{n}} \quad \mathrm{y}_{\mathrm{n}} \quad \mathrm{y}_{\mathrm{n}}$

$\int_{0}^{N(P v, z, k t)} \emptyset(t) d t \leq$

$\int_{0}^{\max } \Phi N(z, z, t) \otimes\{N(z, P v, t) \cdot N(z, z, t)\} \otimes N(P v, z, t) \emptyset(t) d t$

$\int_{0}^{N(P v, z, k t)} \emptyset(t) d t \leq$

$\int_{0}^{\max [1] \diamond\{N(z, P v, t) \cdot 1\} \otimes N(P v, z, t)} \emptyset(t) d t$

$\int_{0}^{N(P v, z, k t)} \emptyset(t) d t \leq \int_{0}^{N(P v, z, t)} \emptyset(t) d t$

By Lemma 2.1, we conclude that $\mathrm{Pv}=\mathrm{Z}$

Since $\mathrm{z}=\mathrm{Sv}$ and we proved that $\mathrm{z}=\mathrm{Pv}$, then from this we get $\mathrm{z}=\mathrm{Pv}=\mathrm{Sv}$, which shows that $\mathrm{v}$ is a coincidence point of the pair $(\mathrm{P}, \mathrm{S})$.

Since $T(x)$ is also closed subset of $X$. There fore $\lim _{n \rightarrow \infty}$ $\mathrm{Ty}_{\mathrm{n}}=\mathrm{z}$ in $\mathrm{T}(\mathrm{X})$ and hence there exists $\mathrm{w} \in \mathrm{S}$ such that $\mathrm{Tw}=\mathrm{z}=$ $\mathrm{Sv}=\mathrm{Pv}$

Now, we will prowe that $\mathrm{Qw}=\mathrm{z}$.

By using in equality (3), putting $\mathrm{x}=\mathrm{v}, \mathrm{y}=\mathrm{w}$, we get

$$
\int_{0}^{M(P v, Q w, k t)} \phi(t) d t \geq
$$




$$
\begin{aligned}
& \int_{0}^{\min [M(S v, T w, t) *\{M(S v, P v, t) \cdot M(Q w, T w, t)\} * M(P v, T w, t)]} \phi(t) d t \\
& \int_{0}^{M(P v, Q w, k t)} \phi(t) d t \geq \\
& \int_{0}^{\min [Q M(z, z, t) *\{M(z, z, t) \cdot M(Q w, z, t)\} * M(z, z, t)]} \phi(t) d t \\
& \int_{0}^{M(z, Q w, k t)} \phi(t) d t \geq \\
& \int_{0}^{\min [1] *\{1 \cdot M(Q w, z, t)\} * 1]} \phi(t) d t \\
& \int_{0}^{M(z, Q w, k t)} \phi(t) d t \geq \int_{0}^{M(Q w, z, t)} \phi(t) d t
\end{aligned}
$$

Similarly,

$$
\int_{0}^{N(z, Q w, k t)} \varnothing(t) d t \leq \int_{0}^{N(Q w, z, t)} \varnothing(t) d t
$$

Hence, from Lemma 2.1, we get $\mathrm{Qw}=\mathrm{z}$.

Combining all results we get $\mathrm{Tw}=\mathrm{Qw}=\mathrm{z}$.

which shows that $\mathrm{w}$ is the coincidence point of the pair $(\mathrm{Q}, \mathrm{T}$ ).

Now, since the pairs $(\mathrm{P}, \mathrm{S})$ and $(\mathrm{Q}, \mathrm{T})$ are semi compatible and hence we get

$\mathrm{PSx}_{\mathrm{n}} \rightarrow \mathrm{Sz}$ So, $\mathrm{Pz}=\mathrm{Sz}$.

and, $\mathrm{QTy}_{\mathrm{n}} \rightarrow \mathrm{Tz}$ so, $\mathrm{Qz}=\mathrm{Tz}$.

Now, we will prove that $\mathrm{Pz}=\mathrm{z}$

Again, using inequality (3), putting $x=z, y=w$, we get

$$
\begin{gathered}
\int_{0}^{M(P z, Q w, k t)} \phi(t) d t \geq \\
\int_{0}^{\min [M(S z, T w, t) *\{M(S z, P z, t) \cdot M(Q w, T w, t)\} * M(P z, T w, t)]} \phi(t) d t \\
\int_{0}^{M(P z, z, k t)} \phi(t) d t \geq \\
\int_{0}^{\min \mid \Phi M(P z, z, t) *\{M(P z, P z, t) \cdot M(z, z, t)\} * M(P z, z, t)} \phi(t) d t \\
\int_{0}^{M(P z, z, k t)} \phi(t) d t \geq \int_{0}^{M(P z, z, t)} \phi(t) d t
\end{gathered}
$$$$
\int_{0}^{\min [M(S z, T u, t) *\{M(S z, P z, t) \cdot M(Q u, T u, t)\} * M(P z, T z, t)]} \phi(t) d t
$$

$$
\begin{gathered}
\int_{0}^{M(z, u, k)} \phi(t) d t \geq \\
\int_{0}^{\min [M(z, u, t) *\{M(z, z, t) \cdot M(u, u, t)\} * M(z, z, t)]} \phi(t) d t \\
\int_{0}^{M(z, u, k t)} \phi(t) d t \geq \int_{0}^{\min [\mathrm{M}(\mathrm{z}, \mathrm{u}, \mathrm{t}) *\{1.1\} * 1]} \phi(t) d t \\
\int_{0}^{M(z, u, k t)} \phi(t) d t \geq \int_{0}^{M(z, u, t)} \phi(t) d t
\end{gathered}
$$

Similarly, we can proved that

$$
\int_{0}^{N(z, u, k t)} \phi(t) d t \leq \int_{0}^{\mathbb{N}(\mathrm{z}, \mathrm{u}, \mathrm{t})} \phi(t) d t
$$

Hence from Lemma 2.1 we get $\mathrm{z}=\mathrm{u}$. This completes the proof.

Corollary 3.2 Let $(X, M, N, *, \diamond)$ be a complete intuitionistic fuzzy metric apace and let $\mathrm{P}, \mathrm{Q}, \mathrm{S}$ and $\mathrm{T}$ be self mappings of $X$ satisfying the conditions of theorem 3.1 and there exists $\mathrm{k} \in(0,1)$ such that for all $\mathrm{x}, \mathrm{y} \in \mathrm{X}$ and $\mathrm{t}>0$,

$$
\begin{aligned}
\int_{0}^{M(P x, Q y, k t)} \phi(t) d t & \geq \int_{0}^{M(S x, T y, t)} \phi(t) d t \\
\int_{0}^{N(P x, Q y, k t)} \phi(t) d t & \leq \int_{0}^{N(S x, T y, t)} \phi(t) d t
\end{aligned}
$$

Then $\mathrm{P}, \mathrm{Q}, \mathrm{S}$ and $\mathrm{T}$ have a unque common fixed point in $\mathrm{X}$.

Corollary 3.3 Let $(X, M, N, *, \diamond)$ be a complete intuitionistic fuzzy metric apace and let $\mathrm{P}, \mathrm{Q}, \mathrm{S}$ and $\mathrm{T}$ be self mappings of $X$ satisfying the conditions of theorem 3.1 and there exists $\mathrm{k} \in(0,1)$ such that for all $\mathrm{x}, \mathrm{y} \in \mathrm{X}$ and $\mathrm{t}>0$,

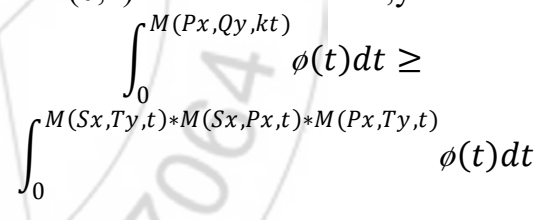

And

$$
\begin{gathered}
\int_{0}^{N(P x, Q y, k t)} \phi(t) d t \leq \\
\int_{0}^{N(S x, T y, t) * N(S x, P x, t) * N(P x, T y, t)} \phi(t) d t
\end{gathered}
$$

Then $\mathrm{P}, \mathrm{Q}, \mathrm{S}$ and $\mathrm{T}$ have a unque common fixed point in $\mathrm{X}$.

Since $\mathrm{Pz}=\mathrm{Sz}$, there for we get

$\mathrm{Pz}=\mathrm{z}=\mathrm{Sz}$

\section{Acknowledgement}

$\mathrm{Qz}=\mathrm{Tz}=\mathrm{z}$.

from this we conclude that

$\mathrm{Pz}=\mathrm{Qz}=\mathrm{Sz}=\mathrm{Tz}=\mathrm{z}$,

which implies that $\mathrm{z}$ is a common fixed point of $\mathrm{P}, \mathrm{Q}, \mathrm{S}$ and $\mathrm{T}$.

\section{Uniquness}

Let $\mathrm{u}$ be another common fixed point of $\mathrm{P}, \mathrm{Q}, \mathrm{S}$ and $\mathrm{T}$.

Then

$\mathrm{z}=\mathrm{Pz}=\mathrm{Qz}=\mathrm{Sz}=\mathrm{Tz}$,

$\mathrm{u}=\mathrm{Pu}=\mathrm{Qu}=\mathrm{Su}=\mathrm{Tu}$.

Now, by using inequality (3), Putting $x=z$ and $y=u$, we get

$$
\int_{0}^{M(P z, Q u, k t)} \phi(t) d t \geq
$$

We would like to thank the feferee for the critical comments and suggestions for the improvement of my paper.

\section{References}

[1] L.A. Zadeh, Fuzzy sets, Inform. Acad Control, vol. 8, pp. 338-355, 1965.

[2] I.Kramosil - J.Michalek, Fuzzy metrics and statistical metric spaces , Kybernetika,,vol. 11(5), pp. 336-344, 1975.

[3] V.George-P.Veeramani, On some results in fuzzy metric spaces, Fuzzy Sets and Systems vol. 64,pp. 395-399, 1994.

[4] M. Grabiec, Fixed points in fuzzy metric spaces, Fuzzy Sets and System, vol. 27 (3), pp. 385-389, 1988. 
[5] A.Branciari, A fixed point theorem for mapping satisfying general contractive condition of integral type, Int. J. Math. Sci. vol. 29(9), pp. 531-536, 2002.

[6] A. Aliouche, Common fixed point theorem via an implicit relation and new property, Soochow J. of maths.vol. 33(4), pp. 593-601, 2007.

[7] M. Aamri and Mautawakil, Some new common fixed point theorems under strict contractive conditions, J. Math. Amal. Appl.vol. 270, pp. 181-188, 2002.

[8] O. A. Boikanyo and B. Choudhary : Some common fixed point theorems for mapping satisfying a general contractive condition of integral type. Int. J. Math. Anal. vol. 1 (24), pp. 1157-1175, 2007.

[9] K.Atanassov, Intuitionistic Fuzzy sets, Fuzzy sets and system, vol. 20, pp. 87-96, 1986.

[10] J.H. Park, Intuitionistic fuzzy metric spaces, Chaos, Solitons \& Fractals, vol. 22, pp. 1039-1046, 2004.

[11]B.Schweizer , A. Sklar , Statistical Metric Space, Pacific Journal Mathematics , Vol. 10, pp. 314-334, 1960.

[12]C. Alaca, D.Turkoglu , C. Yildiz,Fixed Points in Intuitionistic Fuzzy Metric Spaces, Chaos, Solitons and Fractals, Vol.29 No.5, pp.1073-1078, 2006.

[13]C. Alaca, I. Altun ,D. Turkoglu, On compatible mappings of type (i) and (ii) in intuitionistic fuzzy metric spaces, Communication of the Korean Mathematics Society, Vol 23 No.3, pp. 427-446, 2008.

[14]-------, Common fixed point theorems and example in intuitionistic fuzzy metric space , J.K.I.I.S, Vol. 18 No.4, pp. 524-529, 2008.

[15] S. Manro , S.S.Bhatia , S.Kumar, Common fixed point theorems for weakly compatible mapping satisfying common E.A. property in intuitionistic fuzzy metric space using Implict Relation, Journal of Advanced studies in Topology, Vol.3 No. 2, pp. 38-44, 2012.

[16]B.Schweizer , A. Sklar , Statistical Metric Space, Pacific Journal Mathematics, Vol. 10, pp. 314-334, 1960.

[17]C. Alaca, D.Turkoglu , C. Yildiz,Fixed Points in Intuitionistic Fuzzy Metric Spaces, Chaos, Solitons and Fractals, Vol.29 No.5, pp.1073-1078, 2006.

[18]C. Alaca, I. Altun ,D. Turkoglu, On compatible mappings of type (i) and (ii) in intuitionistic fuzzy metric spaces, Communication of the Korean Mathematics Society, Vol 23 No.3, pp. 427-446, 2008.

[19]--------, Common fixed point theorems and example in intuitionistic fuzzy metric space, J.K.I.I.S, Vol. 18 No.4, pp. 524-529, 2008.

[20] S. Manro , S.S.Bhatia , S.Kumar, Common fixed point theorems for weakly compatible mapping satisfying common E.A. property in intuitionistic fuzzy metric space using Implict Relation, Journal of Advanced studies in Topology, Vol.3 No. 2, pp. 38-44, 2012. 